Supporting Information

\title{
A Stable Crystalline Imino-N-Heterocyclic Carbene Ligand and its Corresponding Palladium(II) and Rhodium(I) Complexes
}

Sarim Dastgir, ${ }^{1}$ Karl S. Coleman,${ }^{2}$ Andrew R. Cowley ${ }^{1}$ and Malcolm L. H. Green ${ }^{l}$

${ }^{1}$ Inorganic Chemistry Laboratory, University of Oxford, South Parks Road, Oxford, UK OX1 3QR.

${ }^{2}$ Department of Chemistry, University of Durham, South Road, Durham, UK, DH1 3LE. Email: k.s.coleman@durham.ac.uk (Dr. Karl S. Coleman) 


\section{General procedures:}

- All manipulations were performed under dinitrogen using standard Schlenk techniques or in an inert atmosphere glove box.

- All solvents were dried by passage through an alumina column under a positive pressure of dinitrogen and deoxygenated by bubbling dry dinitrogen through the dried solvents for twenty minutes prior to use.

- NMR spectra were recorded on either a Varian Unity Plus $500\left({ }^{1} \mathrm{H}\right.$ at $500 \mathrm{MHz},{ }^{13} \mathrm{C}$ at 125.7 $\mathrm{MHz})$ or on a Varian Mercury $300\left({ }^{1} \mathrm{H}\right.$ at $300 \mathrm{MHz},{ }^{13} \mathrm{C}$ at $\left.75.5 \mathrm{MHz}\right)$ spectrometer and are at room temperature unless otherwise stated. The spectra were referenced internally relative to the residual protio-solvent $\left({ }^{1} \mathrm{H}\right)$ and solvent $\left({ }^{13} \mathrm{C}\right)$ resonances and chemical shifts were reported with respect to $\delta=0$ for tetramethylsilane.

- Electrospray mass spectra were recorded in acetonitrile on a Micromass LC TOF spectrometer.

- Microanalyses were performed by the Microanalytical Department of the Inorganic Chemistry Laboratory, University of Oxford.

- Gas Chromatographs were recorded using Perkin Elmer XL 1100 instrument with Perkin Elmer NCI 900 Network Chromatography Interface using fused silica, non-polar SGE column 25QC2/BP1 1.0. All GC yields are average of two runs.

- All reagents were purchased from Aldrich, metal precursors from Johnson Matthey and used as received unless otherwise stated. The reagent 1-tert-butylimidazoledazole, ${ }^{1}[\mathrm{Rh}(\mathrm{COD}) \mathrm{Cl}]_{2},{ }^{2}$ COD) $\mathrm{PdCl}_{2},{ }^{3} \pi$-Allylpalladium(II) Chloride dimer $^{4}$ and $\left[\mathrm{Rh}(\mathrm{CO})\left(\mathrm{PPh}_{3}\right)_{3} \mathrm{Cl}\right]$ were prepared using published procedures. The imidoyl chloride was prepared by heating benzanilide and phosphorous pentachloride under vacuum in the absence of solvent. ${ }^{5,6}$ 


\section{Suzuki Coupling Procedure:}

A small Schlenk vessel was charged with $0.5 \mathrm{mmol}$ of ArX, $0.75 \mathrm{mmol}$ of Boronic Acid, $1.0 \mathrm{mmol}$ of $\mathrm{Cs}_{2} \mathrm{CO}_{3}$ or $1.5 \mathrm{~mL}$ of $1.5 \mathrm{M} \mathrm{KOH}$ in deionised water (Table 1 , entry $1 \& 2$ ) and $4.0 \mathrm{~mL}$ of 1,4-dioxane, in a glove box. The catalyst $(1.0 \mathrm{~mol} \%)$ solution in 1,4 -dioxane $(0.25 \mathrm{~mL})$ was added and the mixture stirred at room temperature for 5 minutes. The catalytic mixture was then stirred at $80^{\circ} \mathrm{C}$ for 1.5 hours unless otherwise stated (Table 1) and monitored by GC. For isolation of the products, the contents of the Schlenk vessel were mixed with silica gel and evaporated. The product/silica gel mixture was placed on the top of the flash chromatography column and eluted with a mixture of pentane and diethyl ether (80:20) (Table 1, entry $10 \& 11)$.

Preparation of 4-Acetyl-4'-methylbiphenyl (Table 1, Entry 10): The general procedure for the Suzuki cross coupling reaction affords $98 \mathrm{mg}(94 \%)$ the title compound. The $1 \mathrm{H}$ NMR spectrum matched that of the reported data. ${ }^{7}$

Preparation of 4-Acetyl-4'-methoxybiphenyl (Table 1, Entry 12): The general procedure for the Suzuki cross coupling reaction affords $103 \mathrm{mg}(93 \%)$ the title compound. The $1 \mathrm{H}$ NMR matched that of the reported data. ${ }^{8}$

\section{Typical Hydroformylation conditions:}

Hydroformylation reactions were carried out in an autoclave, equipped with a glass liner and a magnetic stirrer. The Liner was charged with the catalyst ( $1 \mu \mathrm{mol}$ unless otherwise stated), 1-octene $(156 \mu \mathrm{L}, 1.0 \mathrm{mmol})$ and $5.0 \mathrm{~mL}$ of dry toluene. The gauge block assembly was then rapidly attached and the reaction chamber flushed with $\mathrm{CO} / \mathrm{H}_{2}\left(\mathrm{CO} / \mathrm{H}_{2}, 33: 67\right)$. The autoclave was pressurized to the appropriate pressure ( 8 - 55 bar), heated to the appropriate temperature $\left(30-100^{\circ} \mathrm{C}\right)$, and stirred for 24 hours unless otherwise stated. The autoclave was then cooled to room temperature and the pressure released. The contents were transferred to a $10 \mathrm{~mL}$ round bottom flask and $0.2 \mathrm{~mL}$ of cyclohexane as an internal standard was added. The samples were then analyzed by Gas chromatography using a Perkin 
Elmer XL 1100 instrument equipped with fused silica, non-polar SGE column 25QC2/BP1 1.0. and the results reported as an average of two GC runs (Table 2). 


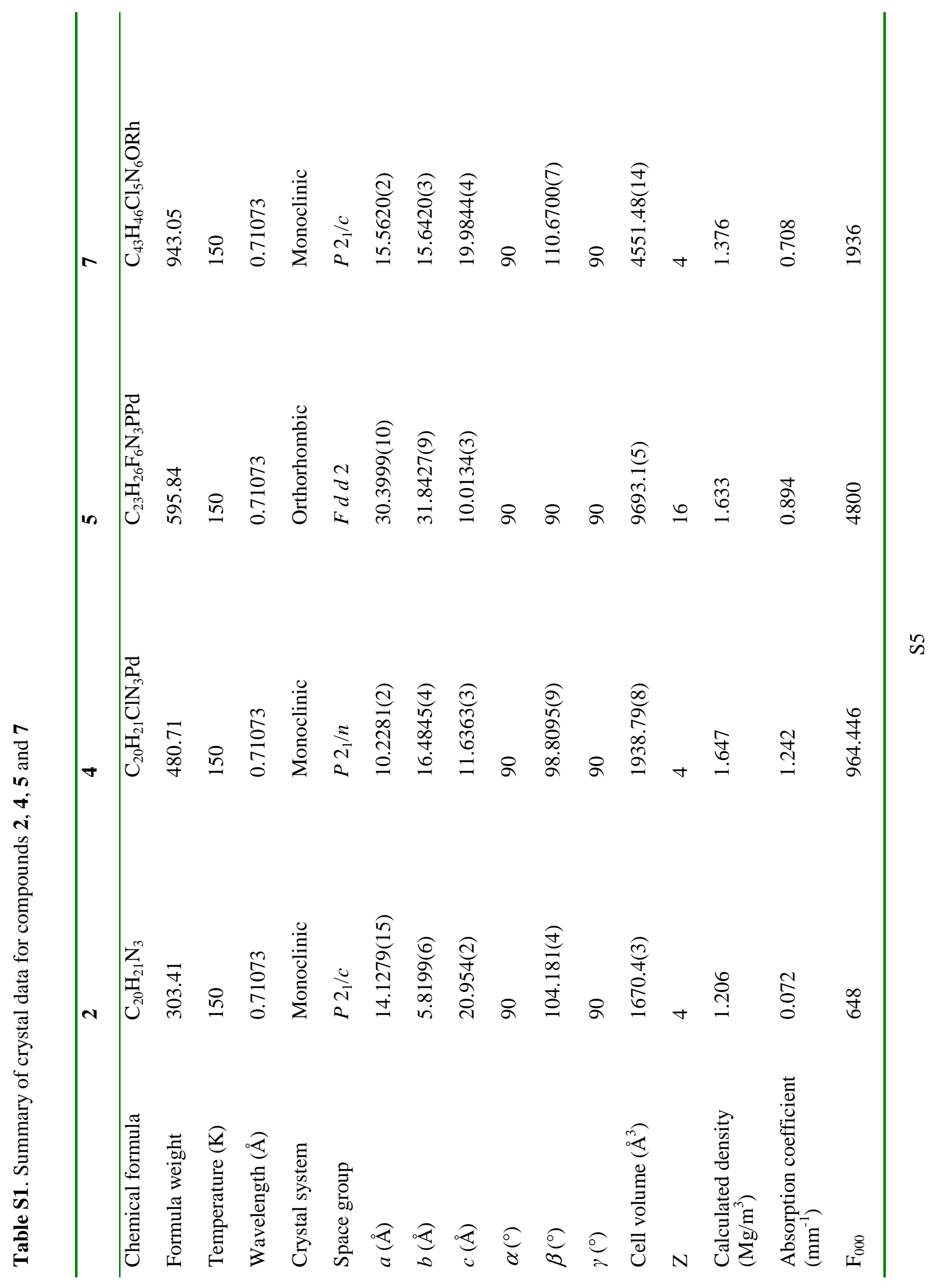




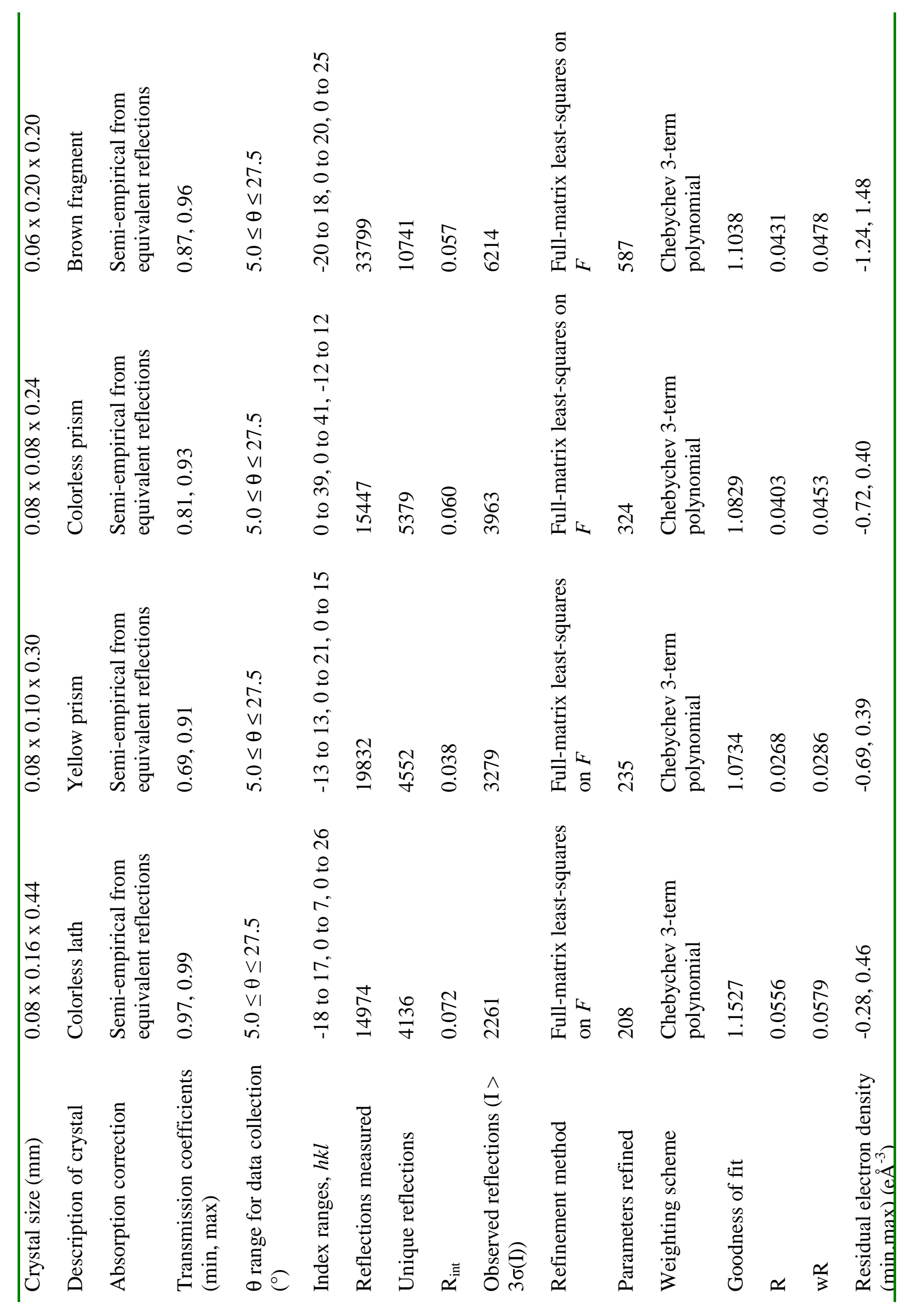

is 


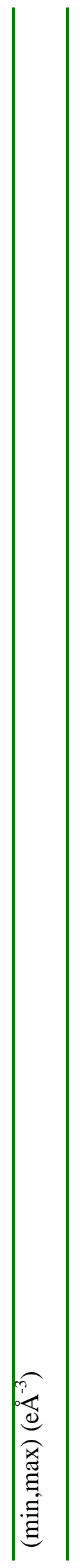




\section{References:}

1. Gridnev, A. A.; Mihaltseva, I. M., Syn. Comm. 1994, 24, 1547-1555.

2. Chatt, J.; Venanzi, L. M., j. Chem. Soc. 1986, 4735.

3. Drew, D.; Doyle, J. R., Inorg. Syn. 1990, 28, 346-349.

4. Tatsuno, Y.; Yoshida, T.; Otsuka, S., Inorg. Syn. 1990.

5. Schenck, T. G.; Bosnich, B., J. Am. Chem. Soc. 1985, 107, 2058-2066.

6. Brindley, J. C.; Caldwell, J. M.; Meakins, G. D.; Plackett, S. J.; Price, S. J., J. Chem. Soc., Perkin Trans. 1: Organic and Bio-Organic Chemistry (1972-1999) 1987, 5, 1153-1158.

7. Ueda, M.; Saitoh, A.; Oh-tani, S.; Miyaura, N., Tetrahedron 1998, 54, 13079-13086.

8. Denmark, S. E.; Sweis, R. F., Org. Lett. 2002, 4, 3771-3774. 